\title{
CBN SMEs Intervention Programmes in Nigeria: Evaluating Challenges Facing Implementation
}

\author{
Joseph E. Tonuchi ${ }^{1,3}{ }^{\dagger}$, Obikaonu C. Pauline ${ }^{2, \dagger}$, Ariolu C. Charles ${ }^{1, *}{ }^{*}$, \\ Nwolisa U. Chinyere ${ }^{1, \dagger}$ and Aderohunmu R. Aderibigbe ${ }^{1, \dagger}$
}

${ }^{1}$ Department of Statistics, Central Bank of Nigeria. and ${ }^{2}$ Department of Financial Market, Central Bank of Nigeria and ${ }^{3}$ Department of Economics, University of Nigeria

*corresponding author: charlesariolu@ymail.com

${ }^{\dagger}$ Auhtors Contributed equally.

\begin{abstract}
Background: To ensure price and economic stability, the central bank of Nigeria has adopted several unconventional monetary policy measure such as SMEs credit intervention with the aim of boosting credit availability in specific sector of the economy. The intuition is that rise in productive activities/investment will indirectly promotes price stability the core mandate of the bank. Therefore, this study investigated the challenges facing implementation of real sector (SMEs) intervention programmes of the CBN since year 2000 to 2020. Method: The study employed mixed method using descriptive survey approach to sample 62 intervention programme implementers and 400 Micro, Small and Medium Sized Enterprises (SMEs). Findings: The findings reveal among others that high loan default risks, politicization of programmes, and inadequate infrastructural development are the leading challenges facing programme implementers in Nigeria. Applicants' non-eligibility in programmes applied for, poor business plan or inadequate knowledge in proposed business topped the reasons for failures among applicant SMEs. Consequently, a need for more public-private partnerships in programme design, monitoring, and evaluation to forestall political interference is advised.
\end{abstract}

Key words: CBN intervention programmes; challenges to intervention programmes; Nigeria; Real sector intervention; SMEs

\section{Introduction}

Small and medium-scale enterprises' (SME) role in achieving economic diversification, solving unemployment, and achieving sustainable economic growth is globally acknowledged in literature. SMEs play significant role in employment generation, economic growth, equitable income distribution, and wealth creation (Oduntan; 2014; Mordi et al.; 2014; Tonuchi and Onyebuchi; 2019). According to Banji (2020) (2020), approximately 96 percent of Nigerian businesses are SMEs compared to 53 percent in the U.S. and 65 percent in Europe. SMEs represent about 90 percent of the manufacturing/industrial sector in terms of number of enterprises. They contribute approximately 48 percent of GDP compared to 62 percent in South Africa and 50 percent in the U.S. or Europe. Also, data from the National Bureau of Statistics (NBS) estimated the total number of SMEs in Nigeria to about 37.07 million, accounting for about 50 percent of industrial jobs and 84 percent of total (PwC; 2020; Udo; 2020).

At the early developmental stages, the contribution of SMEs to GDP is relatively high, as seen in South Africa and other developing countries, but the case is different in Nigeria. Given the potential role of SMEs in developing Nigeria's economy, successive governments have pursued several policy options towards promoting the sector while solving the problem of unemployment, poverty and crawling economic growth in the country (Tonuchi and Onyebuchi; 2019). One of such policy options 
is the introduction of several intervention programmes to increase SMEs' access to finance. Recall that the World Bank Enterprise Survey (2018) identified access to finance as the biggest challenge facing the SMEs, as presented in Figure 1.

To this end, governments at different periods have launched several intervention programmes to increase households' and SMEs' access to credit/finance. While access to finance is arguably the major driver of intervention programmes targeting SMEs in developing countries like Nigeria, there are other reasons the government roll out such interventions, including but not limited to achieving economic diversification, employment generation, and building economic resilience. One question that readily come to mind is whether the several real sector interventions launched in Nigeria have achieved their target objectives? Because SMEs in Nigeria are still struggling to access finance (Ahmed and Dantata; 2003), unemployment in Nigeria remains high and increasing, economic diversification objectives remain a mirage as oil export still accounts for more than 80 percent of Nigeria export (Tonuchi and Onyebuchi; 2019). Understanding why government intervention programmes have not yielded the expected results entails understanding challenges facing the programmes implementation from both implementer and applicant's perspectives.

While no study has investigated the challenges facing intervention programmes implementation from a joint supply and demand sides perspectives to the best of the researchers' knowledge, few have investigated the problem with Nigeria's intervention programmes in general (Oduntan; 2014) or from the demand side (Page and Okeke; 2019; Ogbo et al.; 2020). However, it should be noted that Oduntan (2014) (2014) investigated the challenges to the supply of credit from both the supply and demand side but not in the context of intervention programmes. Regarding the problem facing intervention programmes in Nigeria or elsewhere, Oduntan (2014) (2014) noted that the programmes' biggest problem is policy mismatch and inconsistency. Umana (2018) (2018) argued that a narrow view in the policy formulation and poor implementation is the biggest threat to intervention programmes. Other issues identified in literature include lack of involvement of the target population at the planning phase, poor integration of cultural and social factors while formulating the policies (and these later become the barriers), politicizing the programmes, and concentrating on a single variable. According to Anudu and Okojie (2020) (2020), about 200 of the farmers who benefited from Anchor Borrowers Programme (ABP) fail to repay about N17 billion extended to them by the Central Bank of Nigeria $(\mathrm{CBN})$, and this has exposed the limitations of the real sec- tor intervention programmes. Indeed, while the government can boast of the number of individuals who have benefitted from real sector intervention programmes, to what extent can it boast of funds recovery that will facilitate other programmes? To this end, this study examined the challenges facing the successful implementation of government's MSME intervention programmes in Nigeria from both the supply (implementer) and the demand side (the target beneficiaries). Specifically, the study is guided by the following objectives:

- To determine challenges facing successful implementation of government SMEs intervention programmes in Nigeria.

- Examine challenges that hinder target beneficiaries from successfully participating in government intervention programmes for SMEs in Nigeria.

The rest of the paper is organized into literature review, methodology, analysis and discussion, conclusion and policy recommendations.

\section{Literature Review}

There is no unified definition of SME as the definition(s) rather depend on the nature of industry/industrial capacity as well as the country's level of development, which varies over time (Oduntan; 2014). The difference amongst industries could be ascribed to the different capital requirements of each business. However, the basic definitional parameters remain the same and may include the number of employees, asset base, turnover, and financial strength, among others. In most developed market economies such as the USA, U. K., and Canada the definition criterion adopted is a mixture of annual turnover and employment levels (Oduntan; 2014; Mordi et al.; 2014). The European States traditionally have their own definition of what constitutes SMEs. For instance, Germany's traditional definition limits SMEs to two hundred and fifty (250) employees, while in Belgium it is limited to one hundred (100) employees. Recently, the European Union (E.U.) has standardized the concept by categorizing enterprises with fewer than 10, 50, and 250 employees as 'micro', 'small', and 'medium' enterprises respectively. In the USA, any business with fewer than 100 and 500 employees are classified as 'small' and 'medium' enterprises respectively. In Nigeria, the Small and Medium Industries Enterprises Investment Scheme defines SME as any enterprises with a maximum asset base of N200 million excluding land and working capital and with a number of staff employed

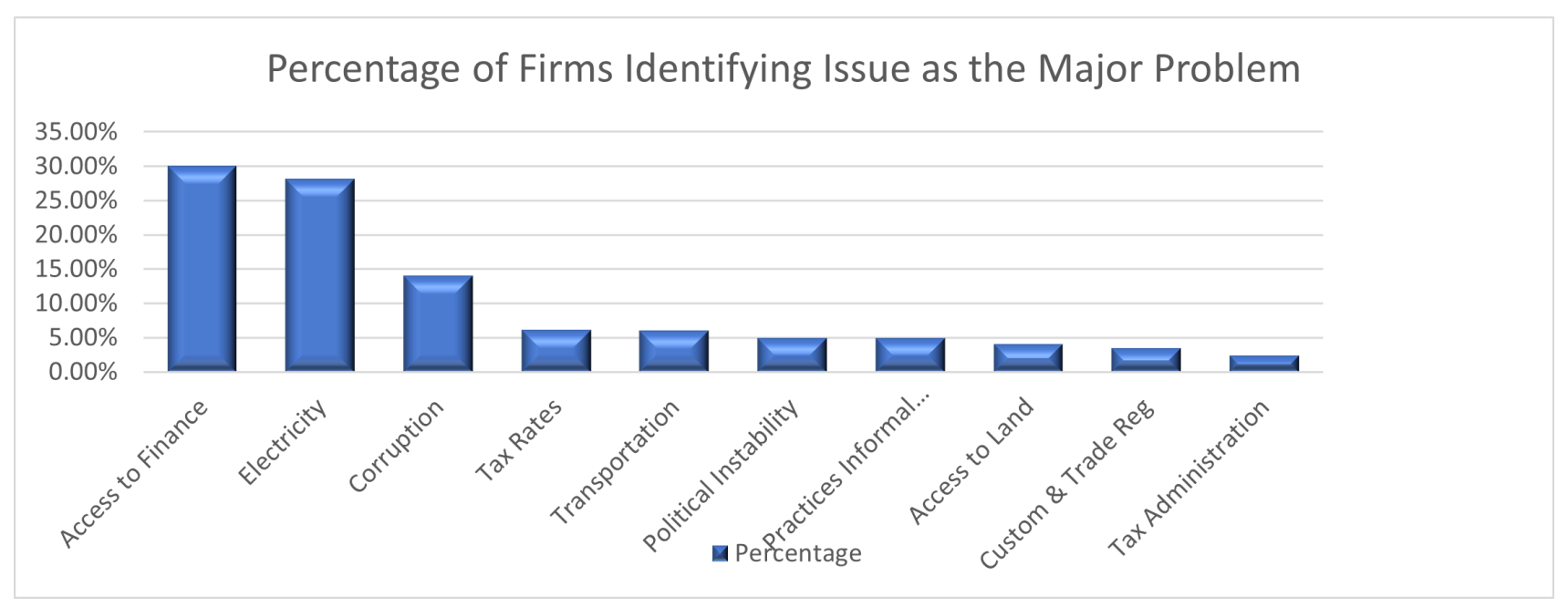

Figure 1. Challenges faced by SMEs in Nigeria. 
not less than ten or more than 300 (Oduntan; 2014).

\subsection{Government intervention Programmes in Nigeria: Disbursements and Challenges.}

\section{Small and Medium Enterprises Equity Investment Scheme (SMEEIS)}

SMEEIS is a voluntary initiative of the Bankers' Committee for the promotion of Small and medium Enterprises (SMEs) as vehicles for rapid industrialization, sustainable economic development, poverty alleviation and employment generation. Its funds were derived from a regulatory 10 percent of banks profit after tax that was to be set aside for loans or equity investment or both in SMEs in Nigeria. With exception of trading and financial services activities, every legal enterprise was eligible for participation. (CBN; 2006). As of June 2009, the Banking Supervision Department of the Central bank reported that a consolidated sum of $\mathrm{N} 42,024,988,746$ had been set aside for the scheme out of which some N28,204,078,292.08 or 67 percent, was extended to fund 333 projects in the 36 states and the FCT (CBN; 2009).

Early assessments of the scheme by Oyefuga et al. (2008) discovered that a significant gap between the funds set aside and what is actually invested in SMEs. This is due, in part, to constraints related to SMEs risk profiles, and to design configurations that are stringent.

Small and Medium Enterprises Restructuring and Refinancing Facility (SMERRF)

The SMERF had the objective of refinancing and restructuring banks' existing loan portfolios to manufacturers to improve access to finance and to improve the financial position of deposit money banks. The loans facilities were administered at 7 percent interest rate and payable quarterly for up to 15 years tenor (Mudashiru; 2016). As at the time of discontinuation in 2015 , the facility was credited to have disbursed up to N381.99 billion to fund some 604 projects in the chemical and plastics, food and beverages, engineering and construction, agro allied, paper and allied products and other sectors of the Nigerian economy (CBN; 2017). Consequently, over 29 thousand direct jobs were created. Though considered successful in achieving its objectives (CBN; 2017), the SMERF is yet to achieve complete recovery of invested funds such that as of 2017 reporting, only 100.7 billion was recovered from the total N381.99 billion invested.

Small and Medium Enterprise Credit Guarantee Scheme (SMECGS)

The SMECGS is a N200 billion fund set up in year 2010 to complement the refinancing and restructuring of banks' loans. Specifically, the SMECGS aimed to provide guarantee for credit from banks to SMEs and manufacturers, increase the access of promoters of SMEs and manufacturers to credit, and set the pace for industrialization of the Nigerian economy (CBN). To that end, it guaranteed 80 percent of bank's loans to the SME sector. As at end of December 2016- six years after inception, only a total of 88 projects valued at $\mathrm{N} 4.3$ billion had been guaranteed along with full repayment of 40 projects valued at N2.2 billion (CBN; 2019). Yet the scheme was largely unassessed due in part to commercial banks' apathy to SME lending as they consider the 80 percent guarantee insufficient motivation to lend from their balance sheets (Mudashiru; 2016).

Power and Airline Intervention Fund (PAIF)

The CBN approved the establishment of the infrastructure finance office in 2010 and subsequently provided a N300 billion Power and Airline Intervention Fund (PAIF). This facility was for investment of debentures of power and airline projects and issued through the Bank of Industry (BOI). Deposit money banks obtained the loans from BOI at a maximum interest rate of 1.0 percent and disbursed same at concessionary rate of not more than 7.0 percent to power/airline projects at a tenor of 10 to 15 years. By end December 2019, the fund disbursed a total of N184.37 billion for 47 power projects, while N120.76 billion was released for 24 airline projects. Repayments in the review year amounted to N26.90 billion, comprising N10.43 billion from airline projects and N16.47 billion from power projects. Cumulative repayment from inception in stood at N172.43 billion, comprising N81.61 billion for airline and N90.82 billion for power projects (CBN; 2019).

Micro, Small and Medium Enterprises Development Fund (MSMEDF)

The CBN launched this development fund in 2013 to further improve and harness the potentials the micro, small and medium enterprises for increasing productivity, employment and wealth creation and inclusive growth. It took off with a N220 billion share capital 10 percent of which was set aside as development component (such as administrative costs) and 90 percent as commercial component to be released to participating financial institutions at 2.0 percent interest for on-lending to SMEs at no more than 9 percent interest rate. As at end December 2019, the cumulative disbursement to SMEs from inception was N83.98 billion and repayment of N35.51 billion. Nonetheless, MSMDEF is hugely untapped by the MSME sector as the participating financial institutions have shied away from the unattractive lending margins and heavy risk profile of SMEs (CBN; 2019).

Paddy Aggregation Scheme (PAS).

The PAS is a working capital facility for integrated Rice millers under the Commercial Agricultural Credit Scheme (CACS). From inception in 2017, it offered 9.0 percent interest rate loans for six months tenor as well as a concessionary waiver of the single obligor limit under the CACS (CBN; 2017). As at end December 2019, 26 millers benefited from a cumulative fund release which stood at N92.33 billion. Repayment is recorded to be N43.21 billion (CBN; 2019). However, as at mid-year 2020, N3.20 billion was further released in favor of 3 additional projects ( $(\mathrm{CBN} ; 2020)$. As evident from a mere 46 percent repayment record, loan default rates may be plaguing the scheme.

\section{CBN Creative Industry Fund Initiative (CIFI)}

In collaboration with the Bankers' Committee, the CBN introduced the N22.9 billion worth CIFI in 2019 with a view to boost job creation in Nigeria, especially among the youth population. CIFI has a main objective of improving access to long-term and low-cost finance to entrepreneurs in the creative and information technology sub-sectors. As at end December 2019, the sum of N653.58 million had been disbursed for 80 projects (CBN; 2017). Also, by half year 2020 , about additional N1.10 billion was disbursed in favor of 160 new beneficiaries (CBN; 2020). Given the minimum and maximum 3 and 10-years loan tenure for the Student Software, Movie production and Music distribution components respectively, it is too early to evaluate the successes or otherwise of the CIFI.

Indeed, CBN have actively striven to fulfill its development mandate through these interventions with a view to encourage businesses in Nigeria's real sector so as to improve employment, and reduce unemployment. In addition to the above, other interventions have included the Agribusiness/Small and Medium Enterprises Investment Scheme (AGSMEIS), the Export Development Facility (EDF), the CBN Anchor Borrowers Programme (ABP), Non-Oil Export Stimulation Facility (NESF) and, in response to the pandemic, some stimulus policy measures such; the Targeted Credit Facility (TCF), COVID19 Intervention Facility for the Manufacturing Sector (CIFMS), 
the Health Care Sector Intervention Fund (HSIF), and the Health Sector Research and Development Intervention Scheme (HSRDIS).

\subsection{Challenges to policy implementation: Empirical Evidence}

Several empirical studies have investigated government intervention programmes' challenges either from a general note, the demand, or the supply side. For instance, Page and Okeke (2019), using a descriptive survey to collect relevant data, highlight corruption, lack of stakeholder consultation in programme design, mismanagement, poor implementation, monitoring, and little impact assessment of interventions as challenges militating against government's MSMEs interventions in Nigeria. The finding is consistent with the work of Ketley (2012) who earlier used similar methodology. Specifically, Ketley identified the challenges to effective implementation of government interventions via agricultural credit guarantee schemes funds to include low level of confidence of banks in government's commitment to the pledged guarantees, complexity in evaluation and management of state-owned credit institutions such as the National Economic Reconstruction Fund (NERFUND), as well as limited awareness of such interventions.

Oyefuga et al. (2008) make similar findings in a study of SMEs in Lagos state where low information or awareness of the interventions contribute to the lopsided implementation of the programmes and the untapped funds of the defunct Small and Medium Enterprises Equity Investment Scheme (SMEEIS).

However, studies like Mordi et al. (2014), who investigated the direction and flow of credits to businesses post bank consolidation in Nigeria, using both cross-sectional and time series data, uncover some supply (implementer) and demand (beneficiary) side constraints to the SME sub-sector. The study reveal that the supply-side challenges are inconsistency in government policies and loan diversion risks. Other factors include information asymmetry issues that weigh heavily on the demand side as various government SME intervention initiatives are less popular amongst the target beneficiaries. For example, a popularity score of such targeted intervention schemes as the MRRF, SMEEIS, SMECGS, CACS, and the ACGS all polled less than 30 percent awareness scores from the SME operator respondents.

On the demand side, the constraints are not totally different from the supply side. For instance, Ogbo et al. (2020) examine SMEs' challenges in accessing government funding and identify process bottlenecks as posing the greatest and statistically significant obstacles to businesses in accessing business creation funds. A similar view is shared by Fred and Omotayo (2018) when they conclude that the bureaucratic bottleneck and cost of assessing funds often hinder SMEs' business expansion or participation in the intervention programmes. This is in concurrence with the earlier findings of Njemanze and Ifeanacho (2011), who conclude that the gap between policy and policy implementation is an inhibitor of SMEs in the State in contributing effectively to sustainable development. They thus attribute failure of the programmes to inadequate awareness and bureaucratic bottlenecks.

Adelaja (2003) identifies a lack of proper and accurate accounting records, fear of dominance or ownership hijacking by equity funders, non-segregation of personal assets from that of the business, and preference for typical bank lending to equity participation by entrepreneurs as challenges encountered by Unity Bank Nigeria Plc. (UBN Plc.) in the administration of the SMIEIS. Similarly, Oyefuga et al. (2008) added that presen- tation of uncoordinated business plan proposals, non-bankable projects, rank high among factors that discourage SME lending by banks or other intervention institutions.

Empirical literature also suggest that the successful implementation of interventions programmes for SMEs is also depended on an economy's level of financial system development as well as other legal and regulatory characteristics (Ayyaggari et al.; 2003). For example, Salami (2003) believes that a stable macroeconomic environment, conducive legal and regulatory frameworks, and sound financial system all have possible implications for implementing public credit intervention schemes for SMEs, such as the SMIEIS.

Also, Helberg (2003), posit that improving the monitoring and evaluation of interventions - aspects of a wider regulatory environment, will enhance intervention outcomes. On their part, Mikloda and John (2018) argue that successful implementation of CBN's interventions in the agricultural SME space could be affected by the bank's ability to mitigate the risks peculiar to the sector while designing interventions. These factors notwithstanding, certain features of SMEs also impede successful implementation of interventions towards development.

For instance, Nhantumbo et al. (2016) conclude that SME development does not seem to be hampered by lack of potential investment funding, but rather by barriers such as 'fear of risk' by both financing institutions and SMEs' 'poor business capacity'. Thus, to build SMEs business capacity, they advise an innovative public finance mechanisms and publicprivate partnerships that include appropriate environmental and social criteria. The literature is indeed rich in the dynamics of SMEs' access to credit in both developed and emerging economies. However, in Nigeria the focus has- for reasons not too far from the popular appeal of national institutional underperformance narrative- been more on the demand side challenges. Little attention is thus given to the supply side challenges constraining implementation of the intervention programmes. Thus, in this work, we attempt to explore such challenges to contribute knowledge and elicit more interest therein.

\section{Methodology}

\subsection{Population, Sample size, and Sampling}

The study population was grouped into two. The first sample focused on intervention programmes implementers (supply side). This includes those involved in the design, planning, implementation, and evaluation of government interventions currently or in the past. To this end, the study targeted the coordinating officers of the different Central Bank of Nigeria interventions from the 36 states pf Nigeria and Abuja the Federal Capital Territory. The sample also include the coordinating officers of the CBN Micro finance Bank (NIRSAL) and other partnering agencies. Of the 72 coordinating officers contacted for the survey 52 of them accepted and participated in the survey within the implementer's categories.

Similarly, the second population category consists of all SMEs that are eligible to participate in any of the present or past government intervention programmes in Nigeria. Because of the large number of firms within this category, the researchers limited the study sample to South West Nigerian. South West Nigeria is considered appropriate given that the region has the largest SMEs presence in Nigeria. Southwest is made up of six states viz: Lagos, Ogun, Ondo, Osun, Oyo, and Ekiti. Of the six states, the researchers randomly selected three (3) states - Lagos, Ogun, and Osun for data collection. Available data from SMEDAN/NBS 2017 survey revealed that SMEs in 
Lagos is 8,395 , while 2465 and 3007 are the number of SMEs in Ogun and Osun state respectively. Using Taro Yamane formula, $\left(n=\frac{N}{\left(1+N e^{2}\right)}\right.$, the sample size is 400 . To select the respondents in each of the three states, the researchers employed a combination of purposive and accidental sampling techniques to target mostly micro and small-scale enterprises in each of the three states. The study considered several factors in its choice of non-probability sampling in reaching the target audience, including the risk associated with the current global coronavirus pandemic, time it takes to obtain consent from firms, available data on SMEs, among others. For instance, the Covid19 pandemic risk limited the researchers to sample only firms whose contacts are obtainable from public domain.

Also, to ascertain the level of awareness of government intervention programmes in the country, the study did not limit the participants to only those who have benefited from any government interventions. To this end, the researchers selected 200 firms from Lagos state and 100 each from both Ogun and Osun states, making 400 respondents. The choice of 200 SMEs from Lagos is because the state houses the largest share of SMEs in the country.

\subsection{Research Instrument and Reliability test}

The researchers specifically relied on Microsoft form to distribute the questionnaire and interview questions to the respondents through email or WhatsApp contacts. To ensure reliability and validity of the research instrument, the researchers conducted a pilot study of 5 SMEs in Ogun state with an average Cronbach Alpha of 0.73 and Duarte and Amaro (2018) (2018) has argued that a Cronbach Alfa above 0.7 is ideal to guarantee relibility of the intrument. Also, the feedback from the pilot study was also used to modify both the questionnaire and interview questions.

\subsection{Estimation and Data Analysis}

To ascertain the significance of each of the challenges, the onesample t-test approach was employed. The one-sample t-test aims to establish if the sample mean is significantly different from the hypothesized mean. The one sample $t$-test is built on the assumption that;

$$
H_{0}: U=U_{0}
$$

$$
H_{1}: U \neq U_{0}
$$

where $H_{0}$ depicts the null hypothesis, $H_{1}$ depict the alternative hypothesis, and $U_{0}$ depicts the hypothesized mean or population mean. Conventional papers employing one sample t-test, the sample size, $\mathrm{t}$-value (an indication of the test strength), and the standard deviation (the degree of consistence among the respondents) are commonly reported (Ling; 2002; Tenga and Aigbavboa; 2020). The null hypothesis holds that each of the challenges is not critical $\left(H_{0}: U=U_{0}\right)$, while the reverse is the case when $H_{1}: U>U_{0}$. To this end, the rating assigned higher value ( 5 and 4 ) to agreement and lower value ( 1 and 2 ) to disagreement, and 3 to neutral/constant and $U_{0}$ is fixed at 3.5. NVivo software and SPSS was utilized to analyze the data.

\section{Result and Discussion}

This section discusses the result of the fieldwork. From the preliminary review of the findings as presented in Table 1, it was
Table 1. Respondents years of experience and type of program involved

\begin{tabular}{llll}
\hline Experience & $0-3$ years & $4-6$ years & above 6 years \\
\hline \multirow{3}{*}{ Program type } & $1.9 \%$ & $25 \%$ & $72 \%$ \\
& Design & Implementation & Evaluation \\
& $8.3 \%$ & $54.2 \%$ & $29.2 \%$ \\
\hline
\end{tabular}

Source: Authors

discovered that of the 52 government intervention programmes implementer sampled, 1.9 percent has $0-3$ years of experience, 25 percent has 4-6 years of experience, while 73 percent has above 7 years of experience. Of these individuals, 8.3 percent have at one time participated in programme design, 54.2 percent participated in programme implementation, while $\mathbf{2 9 . 2}$ percent noted they have participated in evaluation and monitoring.

Drawing insight from the literature reviewed and pilot study, the researchers developed some possible construct of the challenges often faced by both the implementer of the intervention programmes and the challenges SMEs often encounter while applying. However, the researchers further tried to allow the respondents to provide more detailed insight by incorporating structured interview questions to collect information and obtain some peculiar insight that the researcher might not be aware of.

\subsection{Challenges to Successful Implementation of Gov- ernment Intervention Programmes on SMES in Nige- ria}

Table 2 presents responses to the challenges facing policy implementer from successful execution of the programmes from the questionnaire while the responses from the structured interview question is thematically presented afterward. From Table 2, factors such as high risk of loan default, politicization of the programmes, poor state of infrastructure, corruption and nepotism by implementers were ranked high and significant by the respondents. This is shown by the construct's high mean values, above 3.5 and low standard deviation below one. Tenga and Aigbavboa (2020), argued that a standard deviation value that trends below one depicts consistency in respondents' reaction on a particular issue. Similarly, factors such as inadequate funding and technical issue expenses were considered insignificant as their mean values are lower than the 3.5 benchmark.

Comparing with the structured interview responses, the respondents were asked to suggest all the challenges they often faced. Their responses were similar to the findings in table 2. Using NVivo software and thematic coding, seven common themes were identified from their responses.

1. Politicization of the programme: As much as 56 percent of the respondents identified politics or intrusion in the programme by politicians as the common challenge they often encounter during the design, implementation, and evaluation of the programmes. In the words of one of the respondents, "political interference in design and implementation is serious issues and often hamper the process".

2. Poor and inadequate planning at design and implementation level: Inadequate planning leading to policy mix and duplication is another factor commonly voted for by the respondents, with more than 30 percent indicating this as a major concern. In the word of one of the respondents, "inadequate planning before implementation is our problem." Another shared the view that "...politics is a major constraint and lack of good planning whereby we do not test run programmes before rolling them out, we just roll out programmes to satisfy the demand 
Table 2. Challenges to Successful Implementation of government intervention programmes on SMES in Nigeria (Implementer Perspective)

\begin{tabular}{llllll}
\hline & Agree category SA+A & Disagree category (SD+D) & Mean & Std. Dev. & Rank \\
\hline High risk of loan default & 91.6 & 4.2 & 4.33 & 0.76 & 1st \\
Politicization of the program & 79.1 & 8.4 & 4.26 & 0.86 & 2nd \\
Poor state of infrastructure & 79.1 & 16.7 & 4.17 & 0.87 & 3rd \\
Corruption and nepotism by implementer & 76.7 & 12.5 & 4.11 & 1.16 & 4 th \\
Poor communication and coordination & 87.5 & 8.3 & 4.08 & 0.83 & 5 th \\
Poor identity management system & 79.2 & 4.2 & 4.0 & 0.78 & 6 th \\
Goal mismatch by policy makers & 70.8 & 12.5 & 3.85 & 0.86 & 7 th \\
Poor targeting and planning & 66.6 & 12.5 & 3.83 & 0.87 & 8 th \\
Ineligibility by the applicant & 62.5 & 8.3 & 3.75 & 0.90 & 9 th \\
Ineffective PPP in implementation & 58.3 & 16.7 & 3.58 & 0.91 & 10 th \\
Lack of transparency & 58.3 & 16.7 & 3.56 & 0.98 & 11 th \\
Weak institutional framework & 53.5 & 16.7 & 3.39 & 0.99 & 12 th \\
Technical issues & 50.3 & 20.8 & 3.38 & 0.92 & 13 th \\
High cost of creating awareness & 50.2 & 29.2 & 3.35 & 1.10 & 14 th \\
\hline
\end{tabular}

Source: Authors.

\section{of some politicians".}

3. Technical and Bureaucratic issues: This is another factor identified as a challenge facing the programme implementer, with over 56 percent vote. In the word of some of the respondents, "late disbursement of funds most times reduce trust in the programmes", "...unrealistic collateral security demands and late disbursement of funds". Another respondent noted that "even after meeting all the requirements to access the facility by the applicant, there are no guarantee funds to be approved and is frustrating sometimes". Another respondent had this to say: "late and untimely processing, approval and release of the promises of the programmes which often led to poor repayment and loan recovery e.g. ABP". ... "stringent and cumbersome application process by the $C B N$ which consequently incite reluctance and loss of trust in the programmes by the targeted audience". Ideally, one would not expect such responses from individuals handling or managing the programmes, but it is the reality that requires government attention.

4. Risk of Loan Default: About 36 percent of the respondents, identified the risk of loan default as their major challenge. In the word of some of the respondents, "some beneficiaries don't have intention of paying back at the onset, particularly small-scale farming loans". Another respondent noted that "high rate of defaults is a major challenge because government interventions are always seen as national cake and usually not to be returned." "My problem is insincerity and supply of false information by the targeted population".

5. Applicant knowledge and general program awareness: About 40 percent of the respondents noted that insufficient awareness campaign and inadequate knowledge of the requirements by applicants before application constitute a major challenge to the programme. Here are some of the respondent's direct comments: "... most applicants don't understand the requirements of the programme before application", "too many unprepared/uneducated/unknowledgeable persons trying to access the facility".

6. Infrastructure deficiency: About 36 percent identified infrastructure or identity issues as a challenge at accessing the applicants. "Large numbers of unbanked targeted population", "lack of reliable baseline data to design more impactful programmes", "lack of infrastructural development in the areas of the targeted population. This hinders access to them in time and dissemination of real time information as related to the programmes".

7. Applicants perception about the programme: About 28 percent noted that most Nigerians perceive the programmes from a stereotype view that intervention programmes are grants or that it is meant for individuals and firms with the
Table 3. Target Beneficiaries Basic Information

\begin{tabular}{lll}
\hline Awareness and Participation Rate & Percent \\
\hline Aware of programme & 62.5 percent & \\
Not Aware & 37.5 percent & \\
Participation Rate & 10.6 percent & \\
Not Participated & 89.4 percent & \\
Organization Size & $1-10$ employees & 49.1 percent \\
$11-50$ employees & 37.6 percent & \\
50 and above employees & 13.3 percent & \\
\hline
\end{tabular}

Source: Authors

connection. For instance, one of the respondents noted that "general populace perception of the programme as an avenue to share government money is a problem". Secondly, most applicants do not have a viable working business knowledge but want to access millions" "the natives consider government intervention programmes as grants/national cake which they do not have to repay".

From Table 2 above, both the open-ended and close-ended questions yield almost similar results in terms of the key challenges facing the implementation of intervention programmes in Nigeria. As seen, the politicization of the programmes, risk of loan default, state of infrastructure in Nigeria, lack of transparency, and bureaucracy are the key challenges facing the programmes from the implementers' perspective.

The researchers equally made effort to dig deeper into why most applications fail as presented in Figure 2 below. Common among the issues identified include ineligibility of most applicants, poor business plan or insufficient knowledge of the business idea, no business identity, poor financial record keeping, and insufficient managerial knowledge to run the said business.

\subsection{Hindrance to Successful Participation in govern- ment intervention programmes by SMEs in Nigeria}

Preliminary data from the target beneficiaries indicates a 62.5 percent awareness rate of at least one CBN real sector intervention programme in Nigeria while the participation rate is as low as 10.6 percent by the SMEs. The 10.6 percent includes those who have benefited from the programme and those that might have applied but were unsuccessful. As expected, small scale enterprises with employees from 1-10 dominate the survey as in Table 3.

Table 4 revealed collated responses from the target bene- 


\begin{tabular}{|c|c|c|}
\hline Category & Percentage & Excerpts \\
\hline Eligibility related Issues: & 39.67 & $\begin{array}{l}\text { 1. "Inability to meet basic eligibility conditions...., } \\
\text { 2. "Inability to meet some eligibility criteria (collateral criteria } \\
\text { in most cases)" } \\
\text { 1. ... "poor business plan"... }\end{array}$ \\
\hline $\begin{array}{l}\text { Poor Business plan and } \\
\text { knowledge }\end{array}$ & 22.4 & $\begin{array}{l}\text { 2. "Bogus business plan, no adequate knowledge of the } \\
\text { program, and no plan of repaying the loan". } \\
\text { 3. "outrageous applications, no plan for repayment and lack of } \\
\text { bankable business plans..." }\end{array}$ \\
\hline $\begin{array}{l}\text { Inadequate Record } \\
\text { keeping }\end{array}$ & 20.48 & $\begin{array}{l}\text { 1. "No or poor record-keeping on the engaged business" } \\
\text { 2. "Lack of identity by failing to register their businesses with } \\
\text { the CAC" } \\
\text { 3. "... most don't border to register their business, no bank } \\
\text { account and have no good business record keeping habit." }\end{array}$ \\
\hline Managerial related issues & 17.45 & $\begin{array}{l}\text { 1. "Most of the applicants have not planned on how to utilize } \\
\text { the facility judiciously", } \\
\text { 2. "...No clear vision, ideas and no proper research is done by } \\
\text { the applicants" } \\
\text { 3. "No proper research is done by the applicants and unwilling } \\
\text { to learn..." }\end{array}$ \\
\hline
\end{tabular}

Figure 2. Reasons Why Most Applications Fail.

Table 4. Target Beneficiary views on the Challenges facing their Participation in the Intervention Programmes.

\begin{tabular}{|c|c|c|c|c|c|}
\hline & Agree category SA+A & Disagree category (SD+D) & Mean & Std. Deviation & Rank \\
\hline Poor awareness of the program & $93.3 \%$ & $2.6 \%$ & 4.52 & 0.72 & $1 \mathrm{st}$ \\
\hline Corruption among the program implementer & $91.5 \%$ & $4.9 \%$ & 4.50 & 0.77 & 2nd \\
\hline Politicisation of programme & $91.1 \%$ & $2.6 \%$ & 4.41 & 0.79 & $3 r d$ \\
\hline Lack of transparency & $89.3 \%$ & $4.4 \%$ & $4 \cdot 30$ & 0.85 & 4th \\
\hline Prohibitive collateral requirements & $77.0 \%$ & $7.5 \%$ & 4.11 & 0.79 & 5 th \\
\hline Inadequate knowledge of how to participate & $84.0 \%$ & $3.1 \%$ & 4.07 & 0.80 & 6th \\
\hline Lack of trust on the program implementer & $61.0 \%$ & $11.9 \%$ & 3.59 & 0.90 & 7 th \\
\hline Previous testimony or bad experience & $53.1 \%$ & $2.8 \%$ & 3.51 & 1.01 & 8th \\
\hline Not involving target audience at design & $34.6 \%$ & $46.9 \%$ & 3.48 & 0.94 & 9th \\
\hline Lack of managerial competence & $31.5 \%$ & $42.9 \%$ & 3.45 & 0.87 & 10th \\
\hline
\end{tabular}

Source: Authors

ficiaries. Top among the items identified as key challenges facing target beneficiaries include poor awareness of the programme or insufficient knowledge on how to participate in the programme, politicization of the programmes by the politicians and corruption in the system, lack of transparency among the programme implementer, and prohibitive collateral requirements or excessive process to access the loan. However, factors such as lack of managerial competence in project evaluation by the programme implementers, or lack of involvement of target beneficiaries in the design are identified as insignificant challenges contrary to the findings of (Page and Okeke; 2019; Oduntan; 2014). As in the challenges facing the programmes implementer, politicization, corruption among implementer, lack of awareness, and transparency are commonly voted as major challenges facing the target beneficiaries.

As with the policy implementer, respondent SMEs were asked to share some of their experiences in applying for loans through the programme or possible reasons why they have not participated. The responses are quite expository and similar to the view shared by the policy implementer.

1. Politicization or politics: One common theme among the target audience is the issue of politicizing the scheme by politicians and the programme implementers. Most of the re- spondents lamented that the programme is mostly designed to benefit the politicians, those who have someone at the place of authority or "you know someone who knows someone," as captured by one of the respondents. For instance, one of the respondents noted that "in Nigeria, things like this does not work for an average man because it is all about who you know in the government or in the place of power and authority."

2. Bureaucratic process: "Procedures are sometimes too cumbersome that one doesn't even care any longer about such programmes. "... AGMESIS CBN program has been delayed for more than 8 months since we were interviewed and shortlisted for NIRSAL loan..." For instance, asking for 20 Hectares in a continuous location is too much. Alright, if within same community. Group can put their land together but must be in same location. Asking for 15 years of ownership. Even farm Settlements allocation is yearly though you can continue the use for longer than 50 years and transfer to your children". These are excerpts from the respondents on the process.

3. Awareness: Most of the respondents who noted that their organizations have not participated in the programmes argued that there is insufficient and unclear information on how to apply. Some argued that they were aware but believes that Nigerian factor will always play. One of the respondents said: 


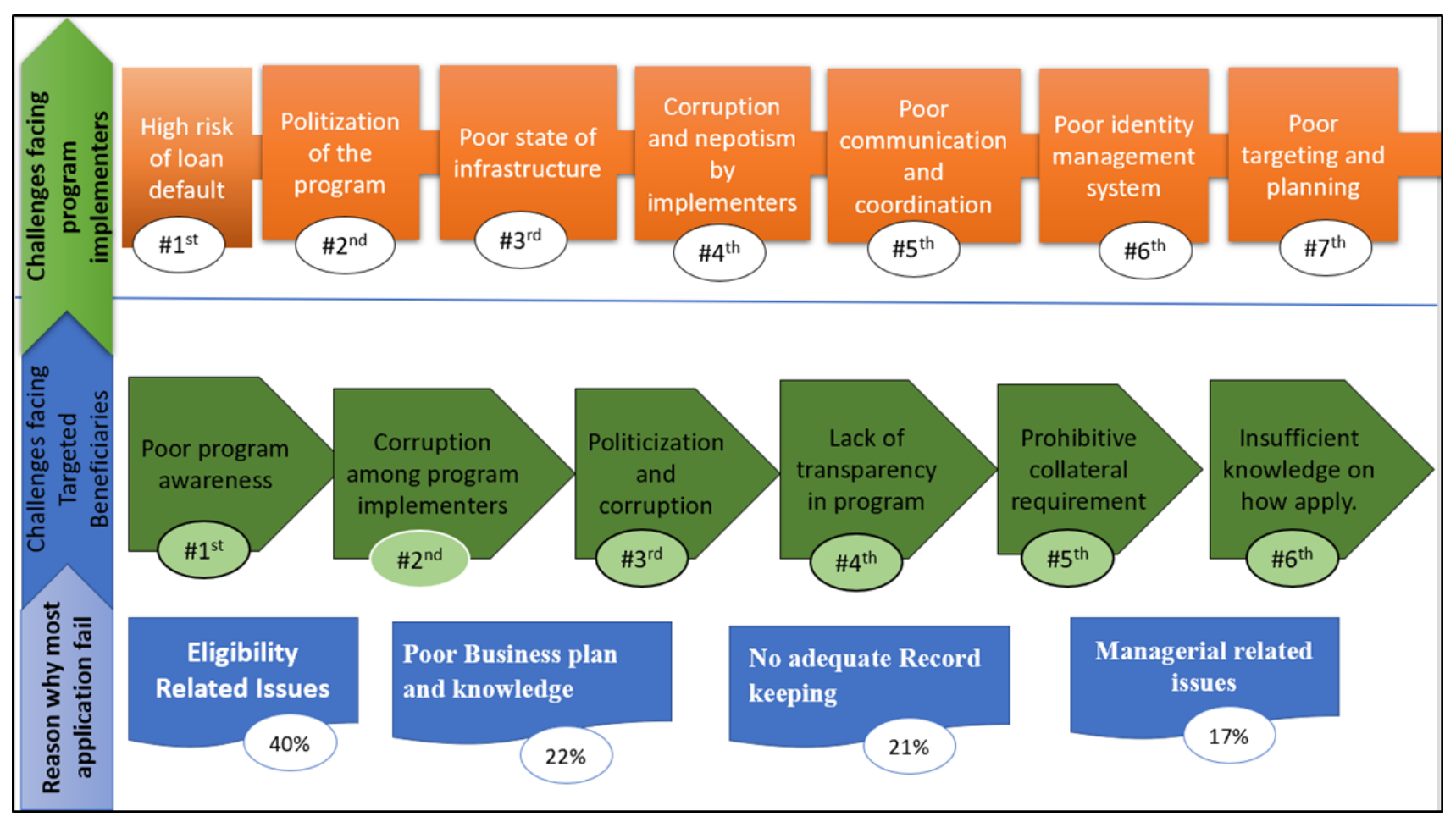

Figure 3. Summary of the challenges facing to intervention Programmes in Nigeria.

"there is no clear information about the different programmes, we have tried two of the programmes and the NIRSAL people are telling us different things from what we saw online".

4. Corruption among implementers: Unexpectedly, this is one point that is highly voted for by most of the respondents in both axes. Most of the respondents believed that policy implementers demand tips and commission to get their application approved. Excerpts from some of the respondents: "The last application was not funny as it was difficult accessing the loan officials. After filling my organization's details, they refused to examine my business plan and insisted that I must pay them to write for me. Which I did; till date I have not heard from them after 10 months of application. If the application is rejected, at least, they should give reasons and allow one to source for alternatives." Another respondent has this to say: "the official told us that if we agree to pay them 10 percent of the approved loan, they will help us to get our loan approved within two weeks, this is not right."

5. Lack of transparency: Some of the respondents also believed there is lack of transparency in the application process. One of the respondents argued that, "the system is supposed to be designed that you (sic) can apply and track the progress of your application". "There is information asymmetry as no information on whether the application through the agency was submitted or treated till date after collecting certificate fee and application fees of N32, 000". Another respondent argued that "it was very frustrating applying after visiting the office several months, yet we did not hear anything from them since about 11 months now".

6. Collateral Requirements: Few respondents complained about collateral requirements and demands. Common complaints include high land demands for Anchor Borrowers Programmes, and the cumbersome process of applying for the loans.

A summary of the challenges facing intervention programmes either from demand or supply side is captured in Figure 3.

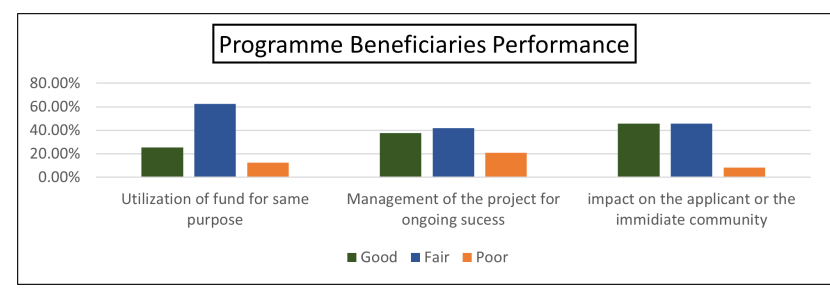

Figure 4. Impact Assessment of intervention Programme on the Beneficiaries

\subsection{Impact Assessment of the Intervention Pro- grammes}

Furthermore, we investigated if existing programmes have yielded any impact on the target beneficiaries in terms of utilization of funds for the purpose of the approved project, management of the organization for ongoing success, and impact on the beneficiaries' immediate community.

Our findings revealed that 26 percent of the policy implementer rated beneficiaries utilization of funds for the loan was obtained good, 61 percent fair, and 13 percent poor. The detailed findings are presented in Figure 4 . Figure 4 clearly revealed that intervention programmes have yielded a significant positive impact on the benefiting organization in terms of continuity, and impact on the immediate community like employment. For instance, benefiting organizations will have the ability to increase their capacity to withstand competition and expand their employment and output. The rise of employment and output of the benefiting firms will increase aggregate demand in the country, which is good for the country's overall health. In a way, one can agree that the intervention programmes have made some significant strides in terms of their impact on the beneficiaries, the immediate community, and impact on Nigeria's economy despite the low participation rate. 


\section{Conclusion and Policy Recommendation}

The study concludes that factors such as high risk of loan default, politicization of intervention programmes, inadequate infrastructural development, high bureaucracy in application process, low level of awareness or participation particularly by targeted beneficiaries, are major challenges facing programme implementers (supply-side constraints). Others include policy duplication or goal mismatch, poor targeting and planning, applicant ineligibility issues and lack of transparency in the system.

Similarly, applicants' non-eligibility for programme applied for, poor business plan or inadequate knowledge of the proposed business for start-up and inadequate record-keepingparticularly for existing businesses- are reasons most applicants fail. Again, from the demand side (applicant challenges and reason target beneficiaries failed to participate in the programme) includes politicizations of the programme, lack of transparency in the application process, corruption among implementer and inadequate awareness.

\subsection{Policy Recommendation}

Given the constant possibility of political interference in MSME intervention programmes, there is need for more publicprivate partnerships in programme design, monitoring and evaluation. This will increase transparency in the interventions, reduce corruption and politicization. Technology adoption can enable applicants' to effectively monitor their applications from beginning to end. This can also be adapted to check the malfeasance among field staff of implementing agencies who might be susceptible to bribery.

To deter purposeful loan defaults and discourage charlatans from applying, BVN can be used to blacklist defaulters. And the management should pursue this to a logical conclusion to ensure continuity of the various programmes. There is a need for a more strategic partnership with the media. Both national and local media should be involved to increase the programmes' awareness. Details of programme application processes should be discussed in the media to increase greater awareness and participation rate.

Establishment of a pragmatic entrepreneurship hub and internship programmes for micro and small scale enterprises applying for the loan. This will come in the form of enrolling start-ups with other firms providing same service they intend to deliver for at least six months as criteria for accessing the loan. To achieve this, the government will need to partner with successful organizations in different industries, particularly past beneficiaries of the programmes. This will eliminate the incidence where applicants simply obtain entrepreneurship training certificates without practical knowledge of managing the proposed business.

The need to create a special agricultural agency. One of the common causes of loan defaults by SMEs and smallholder farmers is lack of market for their produce. To increase agricultural output and encourage production, a specialized agency that will serve as intermediaries between sellers and buyers of agricultural produce should be created. This agency will be able to absorb agricultural market produce during market gluts and reduce the incidence of farmers losing their investment because of low demand during harvest. Such de-risking will encourage more participants in the agriculture value chain. In addition to supply of credit through interventions, farmers and firms in the agricultural value chain should be subsidized to fight food inflation when necessary and ensure that agricultural output prices remain low. This will drive the price of food downward and encourage more participation in the agriculture.

\section{Competing Interests}

Authors declare no competing interest.

\section{References}

Adelaja, B. (2003). Financing small and medium enterprises under smieis: Operators' perspective' in central bank of nigeria., Seminar SMIEIS Lagos 3(1): 100-114. URL: https://www.cbn.gov.ng/OUT/PUBLICATIONS/

Ahmed, I. A. and Dantata, B. S. (2003). Problems and challenges of policy implementation for national development., Seminar SMIEIS Lagos 6(15): 60-65.

Anudu, O. and Okojie, J. (2020). Financing small and medium enterprises under smieis: Operators' perspective' in central bank of nigeria., Farmers' loan defaults show limits of intervention programmes. pp. 1-3.

URL: https://businessday.ng/exclusives/article

Ayyaggari, M., Beck, T. and Demirguc-Kunt, A. (2003). Small and medium enterprises across the globe, World Bank, Policy Research Working paper No. 3127 pp. 1-11.

Banji, O. O. (2020). Sme: issues, challenges and prospects., FSS 2020 International Conference. pp. 1-3. URL: https://www.cbn.gov.ng/fss/wed/SME-Issues

CBN (2006). Revised Guidelines for SMEEIS., Central Bank of Nigeria.

URL: https://www.cbn.gov.ng/OUT/PUBLICATIONS

CBN (2009). Geographic Distribution of SMEEIS Investment, Central Bank of Nigeria.

URL: https://www.cbn.gov.ng/OUT/PUBLICATIONS

CBN (2017). Central Bank of Nigeria Annual Report, Central Bank of Nigeria.

URL: https://www.cbn.gov.ng/Out/2018/RSD/CBN

CBN (2019). Central Bank of Nigeria Annual Report, Central Bank of Nigeria.

URL: https://www.cbn.gov.ng/Out/2020/RSD/CBN

CBN (2020). Central Bank of Nigeria Half Year Report, Central Bank of Nigeria.

URL: https://www.cbn.gov.ng/Out/2020/RSD/CBN

Duarte, P. and Amaro, S. (2018). Methods for modelling reflective-formative second order constructs in pls: An application to online travel shopping., J. Hosp. Tour. Technol. 9(1): 295-313.

Fred, O. P. and Omotayo, A., e. a. (2018). Government financial support and financial performance of smes., Academy of Strategic Management Journal 17(3): 1-10.

URL: https://www.cbn.gov.ng/Out/2018/RSD/CBN

Helberg, P. (2003). A market-oriented strategy for small and medium scale enterprises, World Bank and International Finance Corporation, Discussion Paper No. 40 40: 1-14.

Ketley, R. (2012). Promoting access to credit for msmes through effective government interventions, pp. 1-38. URL: www.efina.org.ng

Ling, R. (2002). The social juxtaposition of mobile telephone conversations and public spaces, Conference on Social Consequences of Mobile Telephones. pp. 1-7.

URL: https://citeseerx.ist.psu.edu/viewdoc

Mikloda, P. I. and John, J. A. (2018). Dealing with risks and uncertainties in agriculture: Implications for central bank of nigeria's interventions, CBN bullion 42(3): 49-68.

Mordi, C. N., Anyanwu, C. J. and et al (2014). Credit delivery to small and medium enterprises: post bank consolidation in nigeria., Occasional Paper No. 53, Central Bank of Nigeria 2(2): 75-78.

Mudashiru, O. (2016). An overview of cbn interventions in the nigerian economy (2009- date)., Proceedings of the Seminar on "Financing Government Programmes in Economic Downturn 
- The Role of Central Bank of Nigeria. pp. 05-08.

Nhantumbo, I., Jones, X., Bolin, A. and Warren, G. (2016). International institute for environment and development., IIED 5: 1-6.

URL: $h t t p: / / w w w . j s t o r . o r g / s t a b l e /$ resrepo262o

Njemanze, V. C. and Ifeanacho, M. I. (2011). Impact of government intervention on the growth of small and medium scale enterprises in imo state, International Journal of Research in Commerce, Economics and Management. 1(7): 1-5.

Oduntan, K. O. (2014). The role of small and medium enterprises in economic development: The nigerian experience, International Conference on Arts, Economics and Management 1(1): 75-78.

Ogbo, A., Arachie, A. E. and Ezema, I. H. (2020). Governance, institutional quality, growth and inequality in africa: A study of the central bank of nigeria., CBN Bullion 44(1): 216.

Oyefuga, I. O., Siyanbola, W, O. and et al (2008). Smes funding: an assessment of an intervention scheme in nigeria, World Review of Entrepreneurship, Management and Sustainable Developmen. 4(2/3): 233-245.

Page, M. T. and Okeke, C. (2019). Stolen dreams: how corruption negates government assistance to nigeria's small businesses., Carnegie Endowment for International Peace, Working
Paper 1. 4: 1-35.

PwC (2020). Nigeria smes survey, World Review of Entrepreneurship, Management and Sustainable Developmen. pp. 1-3.

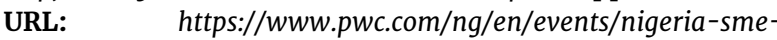
survey.html

Salami, S. I. (2003). Guidelines and stakeholders responsibilities in smieis, A seminal of the Central Bank of Nigeria (CBN) on SMIEIS 4: 50-65.

Tenga, C. and Aigbavboa, C. (2020). Evaluating barriers to effective implementation of project monitoring and evaluation in the ghanaian construction industry, Procedia Engineering 164(1): 389-394.

Tonuchi, E. J. and Onyebuchi, N. A. (2019). Economic diversification in nigeria:the role of agriculture and manufacturing sector, International Journal of Research in Electronics and Computer Engineering 7(4): 916-926.

Udo, C. (2020). Small, medium enterprises account for 84 per cent of jobs in nigeria., Premium Times (1). URL: https://www.premiumtimesng.com/business/

Umana, K. (2018). Problems and challenges of public policies implementation in nigeria, Researchcyber (1).

URL: $\quad$ https://researchcyber.com/challenges-of-public-policyimplementation-in-nigeria/ 